\title{
The American transit of Venus expeditions of 1874 and 1882
}

\author{
Steven J. Dick \\ NASA HQ, Code IQ, 300 E. St. SW, Washington, D.C., USA
}

\begin{abstract}
When in 1874 and 1882 Venus passed in front of the face of the Sun, most countries with a scientific reputation to keep or to gain made plans to observe the great event. The United States was no exception. The purpose was primarily to measure the solar parallax, and thereby determine the astronomical unit, the distance between the Earth and the Sun. With a $\$ 177000$ Congressional appropriation for the 1874 event, and $\$ 78000$ for 1882 , the Americans sent out eight well-equipped expeditions for each transit. Under the U.S. Transit of Venus Commission, the responsibility fell to the U. S. Naval Observatory (Dick 2003). Relying heavily on photographic methods, the Americans returned 350 plates in 1874, and 1380 measurable plates in 1882. Simon Newcomb grew skeptical of the results, but in 1894 William Harkness produced a final value of the solar parallax, after adjustments with other constants, of 8." 809 , with a probable error of 0.'0059, yielding an Earth-Sun distance of 92797000 miles, with a probable error of 59700 miles. This was a significant improvement over previous estimates. How important were the transit of Venus observations? In the end it was Newcomb who had the final say, for it was his system of astronomical constants that was adopted internationally at a Paris conference in 1896. Ironically, just at this time other methods were proving more accurate than Venus transits. In determining a final value for the solar parallax from all methods, Newcomb gave all photographic observations of the 1874 and 1882 transit a weight of 2 , compared to a weight of 40 for Pulkovo Observatory's determination of solar parallax from the constant of aberration. Thus the Venus transit observations played little role in the official value used for the astronomical unit in the 20th century.
\end{abstract}

\section{Introduction}

As the 19th century transits of Venus approached, the phenomenon had been observed only three times in recorded history: 1639, 1761 and 1769. By the 19th century the main interest in observing the transits of Venus, aside from their extreme rarity, was in determining the solar parallax, and thereby the scale of the solar system. At stake was reducing an uncertainty in the Earth-Sun distance by several million miles. Every difference of one hundredth of an arcsecond in the solar parallax, in other words, from 8."79 to 8.' 80 , translated into approximately 100000 miles. The methods had been worked out in the 18th century by Edmond Halley, Joseph-Nicolas D'Isle and others, and required observations from widely varying geographic locations. This inspired expeditions to remote locations around the world, including 8 American expeditions in 1874 and 8 more in 1882 .

Aside from their disputed scientific results, these transit of Venus expeditions are of historical interest for the international disagreements over techniques and instruments, as an early example of international cooperation and rivalry in astronomy, and for their place in two broader historical trends: the determination of the fundamental astronomical constants, and the great scientific voyages of the nineteenth century. A great deal was at stake, not only for science but also for national interests. This is why in 1874 alone the 
British would have 12 expeditions, the Russians 26, France and Germany 6 each, Italy 3 and Holland one. As the 19th century historian Agnes Clerke put it, when in 1874 Venus passed in front of the face of the Sun, "every country which had a reputation to keep or to gain for scientific zeal was forward to cooperate in the great cosmopolitan enterprise of the transit" (Clerke 1902). The United States was no exception; it had a growing reputation in science and was anxious to accelerate that growth. The 19th century transit of Venus pair offered a unique opportunity for the country to showcase its rising scientific talent - one that would not come again until the distant year in the 21st century: 2004 .

\section{Organizing in the United States}

In the United States, Naval Observatory astronomer Simon Newcomb began the discussion of the transits of Venus with a paper in 1870, followed by a resolution before the National Academy of Sciences in April of that year (Newcomb 1870). At the recommendation of the National Academy, in 1871 Congress approved $\$ 2000$ for "preparing instruments." The same bill also provided for Transit of Venus Commission, to be composed of the Superintendent and two professors of mathematics of the Navy attached to the Naval Observatory, the President of the National Academy of Sciences, and the Superintendent of the Coast Survey. In creating a government commission, the United States followed the lead of Germany (1869) and France (1870), while in Britain the responsibilities were shared by the Royal Observatory at Greenwich and the Royal Astronomical Society. The U. S. Transit of Venus Commission as originally constituted included Benjamin F. Sands, Benjamin Pierce, Joseph Henry (President of the National Academy at the time), Newcomb, and Naval Observatory astronomer William Harkness. Only Newcomb and Harkness would survive the full term of the Commission, which held its last meeting and effectively disbanded in 1891, after more than two decades. And of those two only Harkness believed to the end that the method produced a valuable result.

\section{Instruments and methods}

Among the first and most crucial decisions to be made by the American Commission, and by other countries, were the method of observing and the instruments required. The measurement of the relative position of the center of the planet and the center of the Sun was the method of choice, but there was nothing to lose in attempting to measure the exact moment when the planet came into contact with the limb of the Sun. Either method might be attempted visually or photographically, and with photography still in its infancy, especially as applied to astronomy, that decision between visual and photographic methods was by no means a foregone conclusion. But at the urging of Newcomb, from early on the U. S. Commission was drawn to the photographic method, although it hedged its bet by also making visual observations with small refractors.

The photographic method proposed by Newcomb was unique. Unlike most of the European participants, who also opted for the photographic method but devoted their attention to securing the best photographs, the American method proposed by Newcomb concentrated also on the problem of measuring the photograph. Because the measurements on the photograph were made in inches and fractions, Newcomb reasoned, and because the quantity to be determined was in minutes and seconds of arc, a precise knowledge of the scale factor was necessary in order to convert from linear to angular measurement. This conversion, according to Newcomb, was "the greatest difficulty which 

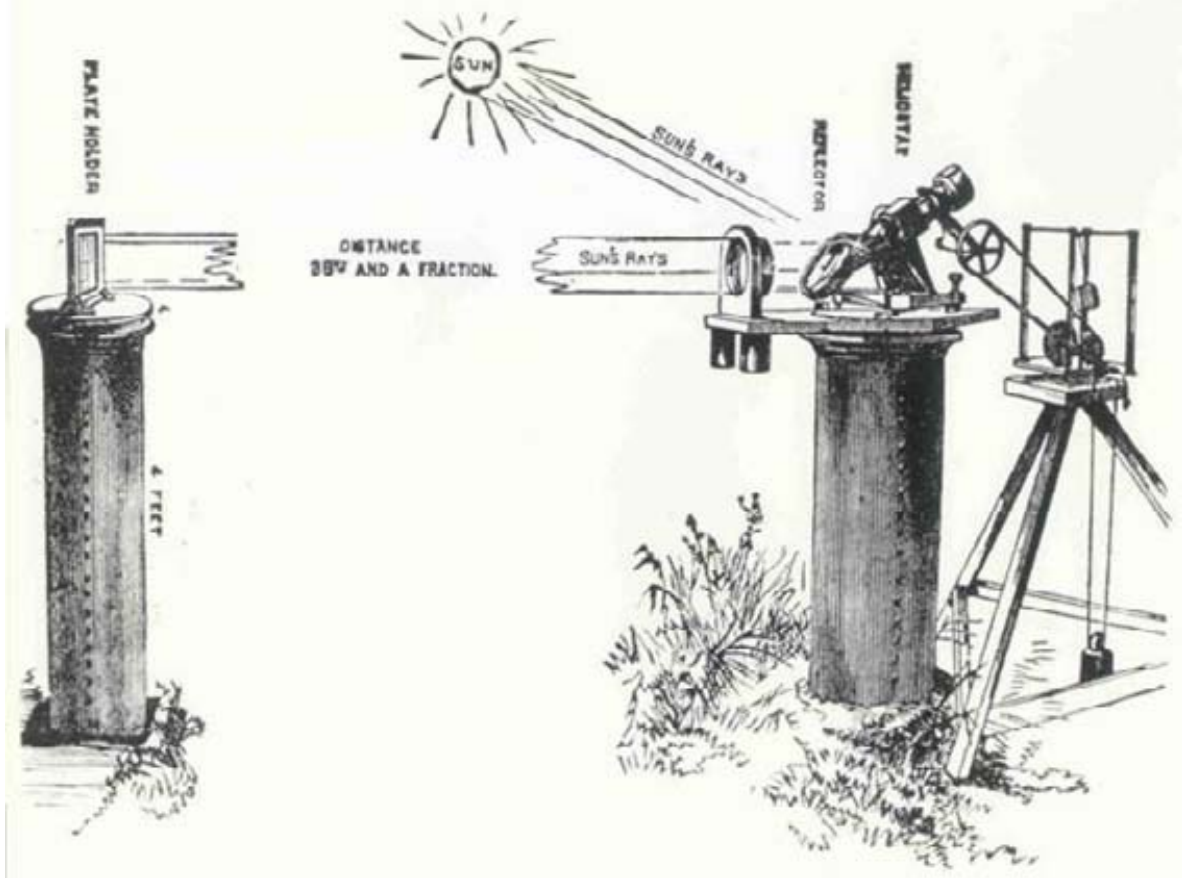

Figure 1. The fixed horizontal telescope known as a photoheliograph, in which a weight-driven heliostat directs the Sun's rays through a lens, which focuses the image onto a photographic plate 38.5 feet away. The method was used by American and French observers. From Simon Newcomb, Popular Astronomy (Haughton and Mifflin: New York, 1878), p. 186

the photographic method offered." To meet it, Newcomb proposed an instrument conceived by Joseph Winlock and already in operation at Harvard College Observatory. This was a fixed horizontal telescope of nearly 40-foot focal length, through which sunlight was directed by a heliostat, a slowly turning mirror that kept the Sun's image stationary with respect to the telescope (Fig. 1). The lens and heliostat mirror - a piece of finely polished but unsilvered glass that reflected about 1/20th of the sunlight into the lens were mounted on a four foot-high iron pier embedded in concrete. The lens, designed to give the best photographic image, formed that image four inches in diameter about 38.5 feet away on the photographic plate. The plate itself was held vertically on another iron stand next to a grid that was overlaid on each photograph for purposes of measurement. A special device consisting of 5 -foot lengths of pipe was used to measure the distance from the lens to the plate within a hundredth of an inch - the crucial measurement on which the scale factor depended. To complete the setup, a transit instrument was to be used to align the system North-South, as well as for other purposes. This photographic method was to be used both for photographs of contact and of Venus as it moved across the face of Sun, with the latter believed to hold the most promise (Newcomb 1872).

At the request of Naval Observatory Superintendent Benjamin Sands, Congress appropriated $\$ 50000$ in June 1872 for the purchase and preparation of instruments, and another $\$ 100000$ in 1873 for the actual expeditions. The following year another $\$ 25000$ was appropriated to complete work and return parties home, for a grand total of $\$ 177000$ for the 1874 event alone, not including salaries and the use of Navy facilities and ships. 


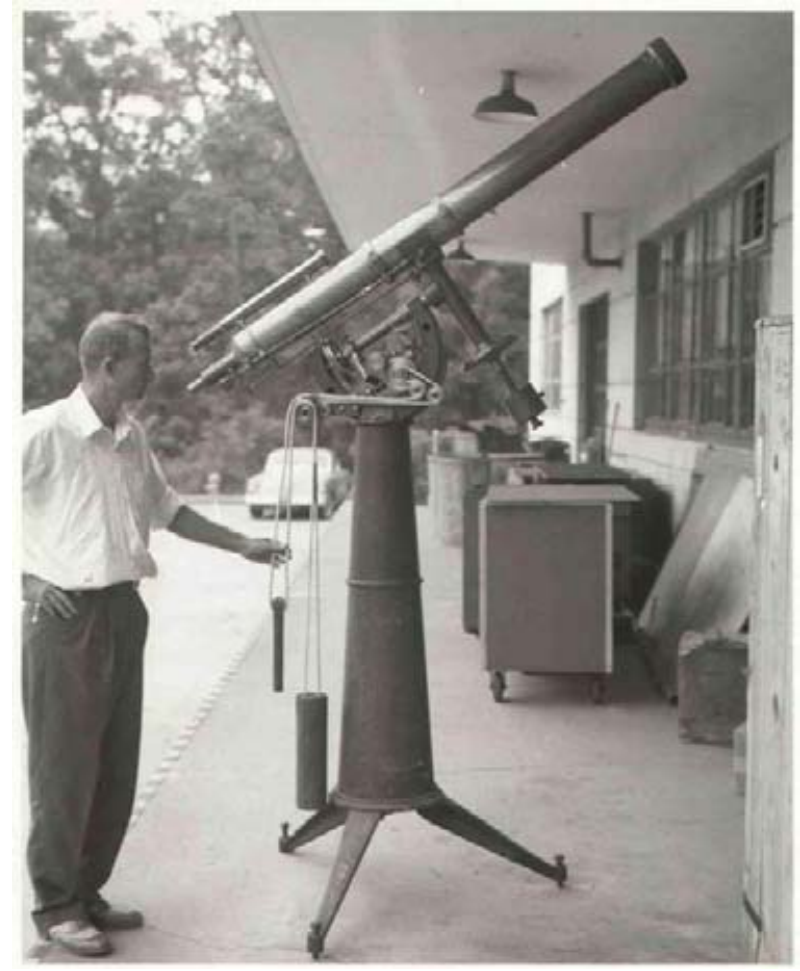

Figure 2. A 5-inch Alvan Clark refractor, one of eight manufactured for the American transit-of-Venus expeditions. Pictured here with Alfred Mikesell at the U. S. Naval Observatory in 1965.

This was a munificent sum indeed, one from which the country might well expect a decent scientific return.

With the first $\$ 50000$ in hand, the Commission held its first meeting on July 22, 1872 , and went to work in earnest on the matters of instruments, choice of stations and organization of the expeditions and their personnel. The Naval Observatory, with the majority of the members of the Transit of Venus Commission including its President (the Superintendent) and Secretary (Newcomb), was authorized to take charge of the details of the expeditions. Harkness drew up the specifications for most of the instruments, eight sets of which had to be manufactured, since the Commission had decided that the appropriation was enough to equip eight American parties. The instruments were constructed by a variety of makers. But for the most crucial of these instruments the Commission turned to Alvan Clark \& Sons, then constructing the Observatory's Great 26-inch Refractor, used by Asaph Hall to discover the 2 moons of Mars in 1877. The firm not only made the 5-inch refractors for the visual observations (Fig. 2), but also the fiveinch 40-foot photoheliograph lenses and the heliostat mirrors crucial for the photographic method, as well as the chronographs for precise registration of time. The polishing of the 7 -inch mirrors, Newcomb recalled, was the most difficult part of the whole apparatus. The accuracy needed to be such that "if a straight edge laid upon the glass should touch at the edges, but be the hundred-thousandth of an inch above it at the centre, the reflector would be useless."

While the visual 5 -inch refractors and the 40-foot photoheliographs were the most important equipment, a broken-tube transit instrument and sidereal clock were also crucial, 
as well as sidereal and mean time chronometers, and a chronograph for registering time. The transit instrument, designed by Harkness and built by Stackpole, was used not only for determining latitude, longitude and time, but also to insure that the central vertical line of the photographic plate holder could be very near the meridian. The clock used with the transit instrument, built by the Howard Clock Company of Boston, was designed for the rugged fieldwork and therefore not particularly elegant.

\section{Stations and personnel}

Once the methods were decided it was necessary to choose the stations. Although the entire transit would last about 4 hours, a very long time compared to the few minutes of totality for a solar eclipse, optimal weather was a prime consideration. To observe the parallax effect, both Northern and Southern Hemisphere stations were required, and after studying weather records it was decided to have three northern and five southern stations. In order to choose the stations, Newcomb began heavy correspondence with U. S. consulates and astronomers around the world. At the suggestion of Struve, Vladivostok was chosen as one northern station, with Nagasaki and Peking the other two. The southern stations chosen were Crozet Islands, Kerguelen Island, Hobart Town (Tasmania), Bluff Harbor (New Zealand), and the Chatham islands off New Zealand. In the end the Crozet Islands site was abandoned when the ship could not land due to severe weather, and two American stations would be located in Tasmania.

The personnel of each station consisted of one chief of party, one astronomer, one chief photographer and two assistant photographers, with a few parties having an additional astronomer and in one case, an instrument maker. The members of the parties were chosen with the greatest care, especially the chiefs and the all-important chief photographer. Two of the chiefs-of-party were from the Naval Observatory, two from the Coast Survey, one from the Army, one from the Navy and two from outside the government. The chief photographers were all professionals in photography, but the assistants were for the most part "young gentlemen of education, recent graduates of different colleges, who had been practiced in chemical and photographic manipulation."

\section{Practice}

For practicing visual observations, beginning in May 1873 an artificial Sun and Venus apparatus was mounted on a building near the War Department, about two thirds of a mile from the Observatory. Using the 9.6-inch refractor, a 5-inch telescope and a 4-inch comet seeker from the dome atop the Observatory, Newcomb, Harkness and Hall repeatedly observed the small black dot representing Venus impinging on the artificial Sun, which was a white circular disk. In the Spring of 1874 many of the participants gathered on the grounds of the Observatory to practice, with goal of improving the accuracy with which contacts could be observed (Fig. 3). At the same time, the photographic apparatus was set up and the photographic process rehearsed, with Henry Draper offering his services to the Commission for several weeks.

\section{Results}

A great deal could be said about the colorful details of the expeditions, the travel problems, the weather problems, the triumphs and heartbreak. But in terms of science, the most important detail is the result. Now began the saga of analyzing the observations. A total of some 350 plates were returned from the 1874 American expeditions. In October, 


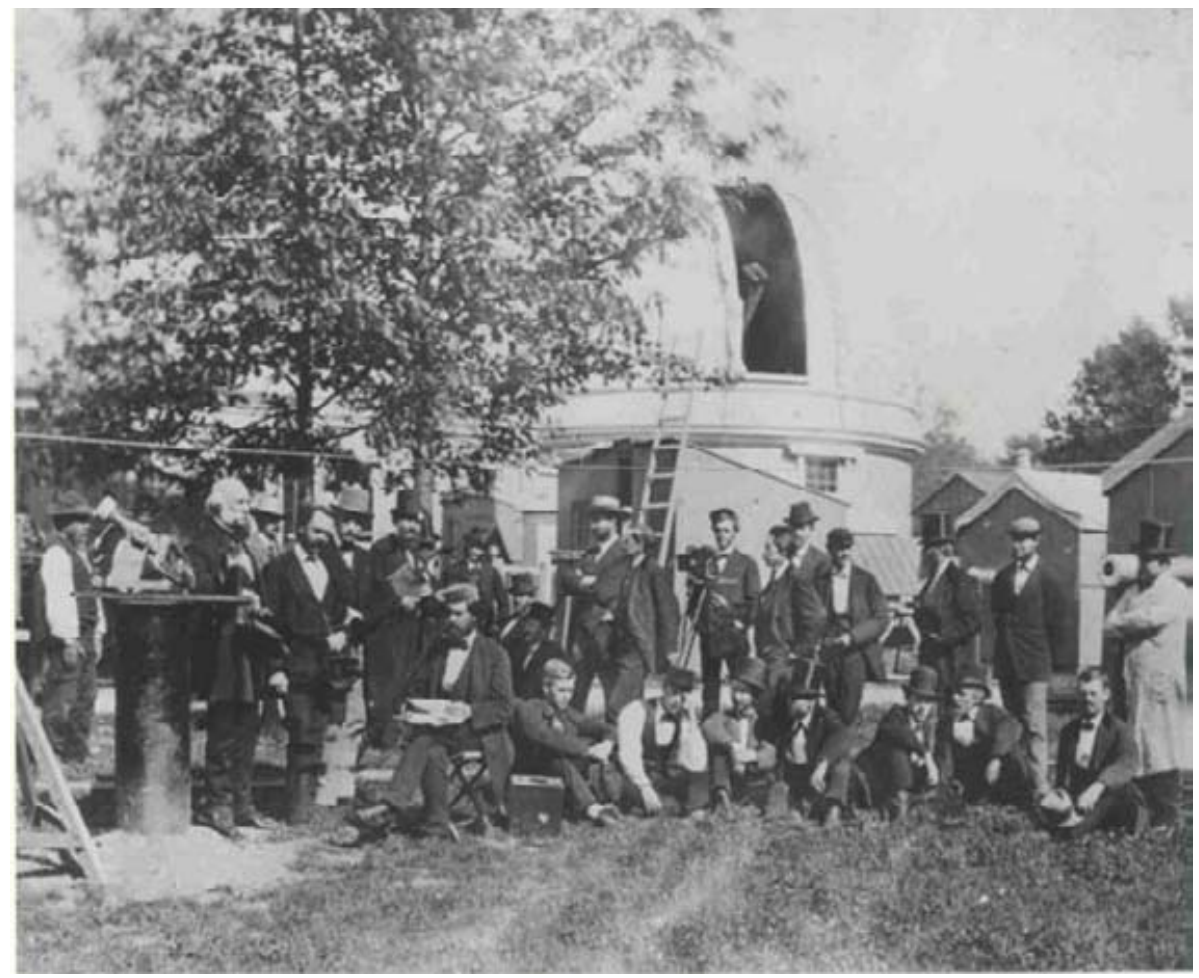

Figure 3. Spring, 1874 practice for transit of Venus on the grounds of the Naval Observatory. Standing at left nearest the photoheliograph is Admiral C. H. Davis, founder of the American Nautical Almanac Office and President of the Transit of Venus Commission at this time. Standing in front of him are Henry Draper and C. H. F. Peters (with hat); seated is Simon Newcomb. Asaph Hall is the tall man in front of the ladder, with hat; at far right (with stovepipe hat) is the Observatory's instrument maker, William F. Gardner. From a set of stereo views of Washington published by J. F. Jarvis, Washington, D.C.

1875 Newcomb still expressed optimism based on what he knew at that point about the observations. The optical observations of contacts made by the observers of all nations would, he believed, "by their combination give a value of the solar parallax of which the probable error will lie between $0.02^{\prime \prime}$ and $0.03^{\prime \prime} . "$ (Recall that means 200000 to 300000 miles). The American photographs alone, he further felt, "will give a result at least as accurate as this, and probably more so." However, Newcomb cautioned, "it is not to be disguised that there is a possibility of unforeseen perturbing causes being brought to light by a comparison of all the observations which will upset all our a priori estimates of probable error." (U. S. Naval Observatory 1875)

Newcomb's cautionary statement proved prophetic. Reporting on the results of the 1874 expeditions eight years later, Harkness recalled that after the parties returned, attention was first turned to the visual contact observations as the easiest to analyze, but "it was soon found that they were little better than those of the eighteenth century." Around the world the result was the same: The problem was that "the black drop, and the atmospheres of Venus and the Earth, had again produced a series of complicated phenomena, extending over many seconds of time, from among which it was extremely difficult to pick out the true contact. It was uncertain whether or not different observers had really recorded the same phase, and in every case that question had to be decided before the observations could be used. Thus it came about that within certain rather 
wide limits the resulting parallax was unavoidably dependent upon the judgment of the computer, and to that extent was mere guesswork." (Harkness 1883).

The photographic observations were thus all the more important, but here again disappointment was widespread. Harkness recalled that "it soon began to be whispered about that those taken by European astronomers were a failure." The official British report declared that "after laborious measures and calculations it was thought best to abstain from publishing the results of the photographic measures as comparable with those deduced from telescopic view." The problem was the Sun itself: "however well the sun's limb on the photograph appeared to the naked eye to be defined, yet on applying to it a microscope it became indistinct and untraceable, and when the sharp wire of the micrometer was placed on it, it entirely disappeared."

All hope focused on the American expeditions, which had returned with about 200 measurable plates in 1874 taken with the long-focus photoheliographs. In June 1875 the Commission charged Harkness with measuring these plates, and he devised a machine especially for this purpose. Harkness reported that 221 photographs yielded "excellent results" for the period between second and third contact when the planet was on the face of the Sun. However, those taken between first and second, and again between third and fourth contacts "proved of no value" because of the infamous black drop problem. In other words, while even long-focus photographic contact observations were no better than visual ones, there was reason for hope in obtaining results from the photographs of Venus fully upon the face of the Sun.

In the end, however, no result of the 1874 American transit of Venus expeditions was ever officially published, although in 1881 D. P. Todd (then an assistant in the Nautical Almanac Office) did publish a brief three-page article in which he determined a provisional value of 8 "' $883 \pm 0$ "' 034 (Todd 1881). By the eve of the 1882 transit the official American results remained uncertain, and it was a heated question whether parties should even be dispatched for the 1882 transit. There were eight more expeditions sent around the world.

To make a long story short, relying heavily on photographic methods, the Americans returned 350 plates in 1874, and 1380 measurable plates in 1882 . And contrary to the common opinion today, a result was produced. Simon Newcomb grew skeptical of the results, but William Harkness (Fig.4) produced a final value, after adjustments with

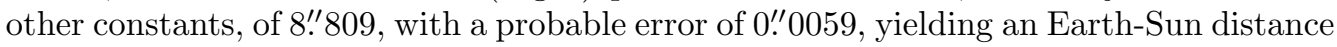
Of 92797000 miles, with a probable error of 59700 miles (Harkness 1891, 1894).

The publication of the official reports of the American Transit of Venus Commission, however, was another matter. Recalling the impressive tomes published by other nations, Harkness argued that the full publication of the American results was essential. His hope in this respect, however, was not realized. Aside from the Papers Relating to the Transit of Venus, and the Instructions for Observing it in 1874 and 1882, only Part I of a projected four parts of Observations was published. Part II, two volumes of reports of the eight 1874 parties and consisting of some description and much data, but no results, reached the page proof stage, and today exist as only a single copy of 564 pages in the Naval Observatory Library. Parts III and IV, which were supposed to be the results, were never published.

The reasons for this failure to publish again were bureaucratic. With the passing of the 1882 expeditions, the Transit of Venus Commission decided it would be best to combine the results of both transits into one report. By 1891, however, despite a recognition of the need "that the United States keep pace with other governments in publishing the results of its observations of these important transits," no further action was taken. The failure to publish an official American report, however, must be distinguished from the 


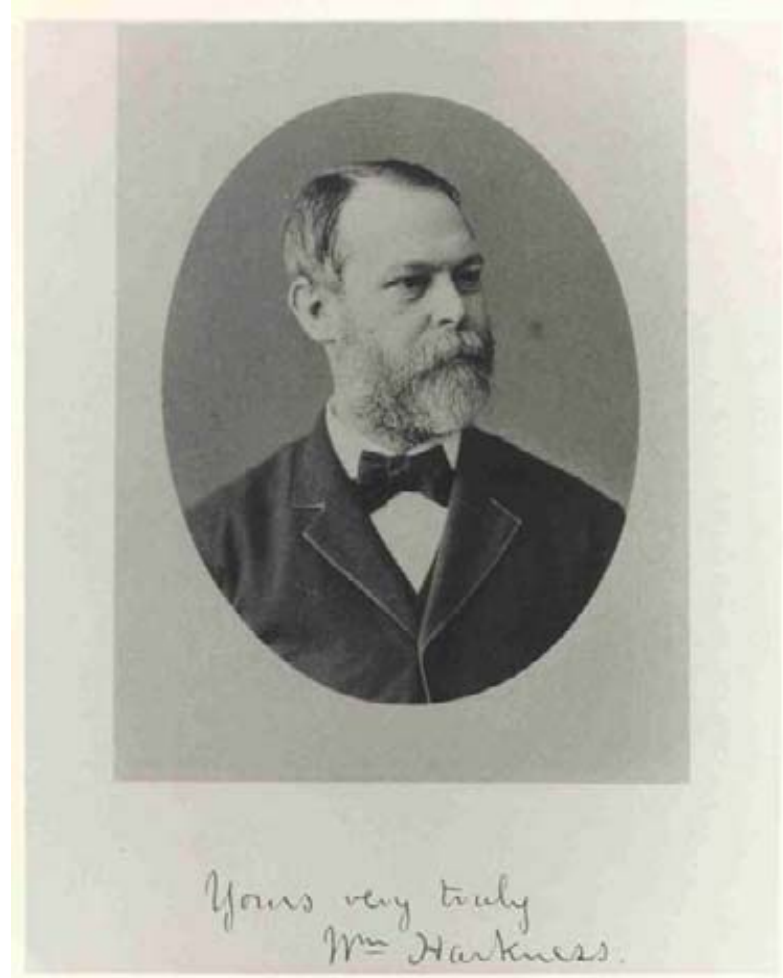

Figure 4. William Harkness, who led the American efforts for the 1882 transit of Venus, and almost single-handedly achieved the final American result.

American result, which was not only obtained but published and discussed in the context of the other astronomical constants by Harkness in the Washington Observations for 1885 (Harkness 1891).

\section{Significance}

How important were the transit of Venus observations? In answering this question we need to recall that the transits of Venus were only one method for determining the solar parallax. Ironically, just as the transit of Venus observations were producing an improved result, other methods became practical that gave even better results. This is true of asteroid parallaxes, but especially of the method involving the aberration of light. From the measurement of the aberration of light one can produce the light time; combined with newly accurate measurements of the speed of light, in which both A. A. Michelson and Newcomb were involved, an accurate distance can be determined. In the end it was Newcomb who had the final say in which methods were applied to the final solution for the astronomical unit, for it was his system of astronomical constants that was adopted internationally at a Paris conference in 1896. In determining a final value for the solar parallax from all methods, Newcomb gave all photographic observations of the 1874 and 1882 transit a weight of 2, compared to a weight of 40 for Pulkovo Observatory's determination of solar parallax from the constant of aberration (Table 1). Considering the probable errors, Newcomb's system and Harkness's system actually overlapped in 
Table 1. Results of Solar Parallax Determinations, with Newcomb's Weights

\begin{tabular}{llr}
\hline & $\begin{array}{l}\text { Solar Parallax } \\
\text { arcseconds }\end{array}$ & Weight \\
\hline $\begin{array}{l}\text { From the mass of the Earth resulting from the } \\
\text { secular variations of the orbits of the four inner planets }\end{array}$ & $8.759 \pm 0.010$ & 9 \\
$\begin{array}{l}\text { From Gilly's observations of Mars at Ascension Island } \\
\text { From Pulkovo determinations of the constant of aberration }\end{array}$ & $8.780 \pm 0.020$ & 2 \\
From observations of contacts during the transits of Venus & $8.794 \pm 0.018$ & 40 \\
From the parallactic inequality of the Moon & $8.794 \pm 0.007$ & 18 \\
$\begin{array}{l}\text { From determinations of the constant of aberration } \\
\text { made elsewhere than at Pulkovo }\end{array}$ & $8.806 \pm 0.0056$ & 28 \\
From heliometer observations on the minor planets & $8.807 \pm 0.007$ & 20 \\
From the lunar equation in the motion of the Earth & $8.825 \pm 0.030$ & 1 \\
$\begin{array}{l}\text { From measurements of the distance of Venus } \\
\text { from the Sun's center during transits }\end{array}$ & $8.857 \pm 0.023$ & 2 \\
\hline
\end{tabular}

From Simon Newcomb, The Elements of the Four Inner Planets and the Fundamental Constants of Astronomy (Washington, 1895), 157. Solar parallax values are arranged in order of magnitude.

their values for solar parallax, and Newcomb came closest to overlapping the modern value of 8 ".794146 (Fig. 5).

By act of Congress dated July 26, 1886, the instruments and records of the Transit of Venus Commission were turned over to the Secretary of the Navy. In that year the instruments, valued at some $\$ 30000$, were made the property of the Naval Observatory, and put into the hands of the Observatory's instrument maker. On April 25, 1891 the Commission held its last meeting, where Harkness reported on the status of the reductions. Along with the effective demise of the Commission, an interesting episode in astronomy passed into history. Today some of the instruments and records remain at the Naval Observatory, and memorial plaques still mark several of the sites of the observations.

The 19th century transits of Venus thus took their place in the long history of attempts to determine the astronomical unit, one of the fundamental constants of astronomy. Without vastly superior methods, Harkness cautioned in his 1894 paper, the value of the solar parallax was not likely to be improved from where it stood after the 19th century transits of Venus. Harkness did live to see the close passage of the minor planet Eros to Earth in 1900-1901, a method that gave a considerable improvement then, and again in 1930-1931.

Just before the 1882 observations, Harkness wrote the following poetic lines:

We are now on the eve of the second transit of a pair, after which there will be no other till the twenty-first century of our era has dawned upon the earth, and the June flowers are blooming in 2004. When the last transit season occurred the intellectual world was awakening from the slumber of ages, and that wondrous scientific activity which has led to our present advanced knowledge was just beginning. What will be the state of science when the next transit season arrives God only knows. Not even our children's children will live to take part in the astronomy of that day. As for ourselves, we have to do with the present ... 


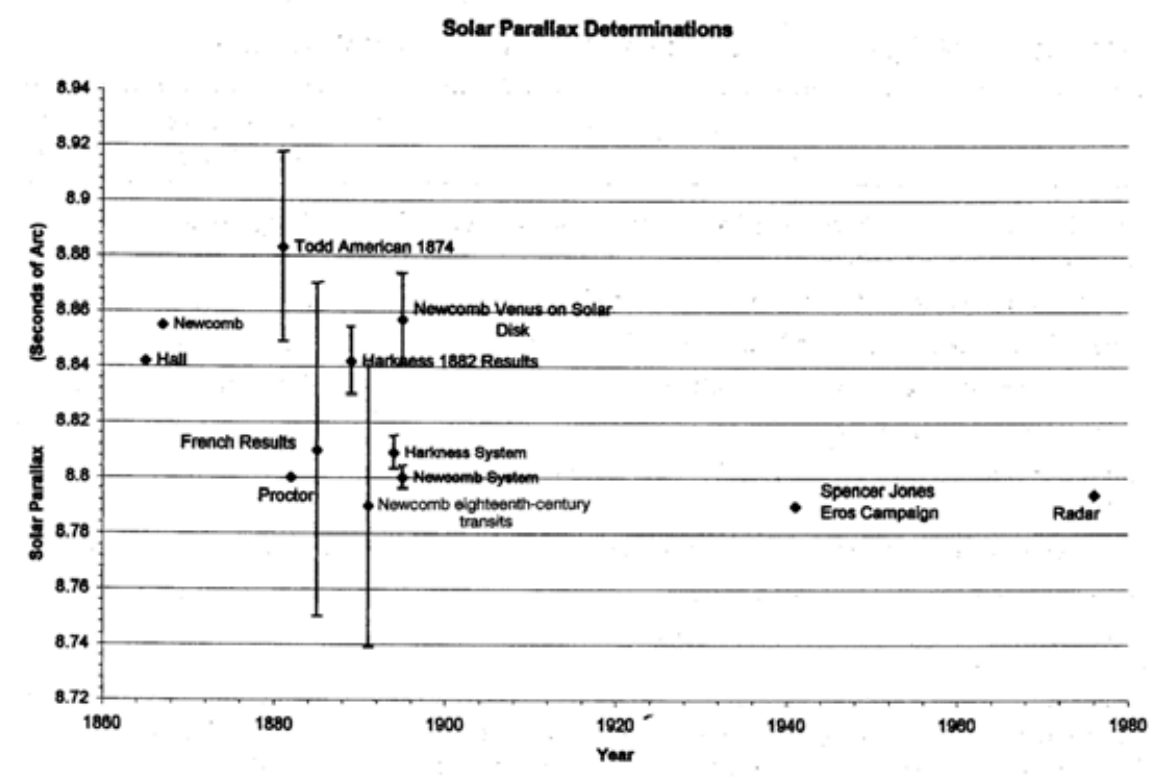

Figure 5. Selected solar parallax determinations, 1860-1976. Aside from the results of Hall and Newcomb in 1865 and 1867 from observations of the meridian parallax of Mars, all 19th century observations shown here were derived from the transits of Venus. Two 20th century results are shown for comparison; their error bars are so small they cannot be seen at this scale.

Harkness would surely marvel that radar methods have now determined the solar parallax to six significant figures, and that the mean distance to the Sun is known within a few meters. And he would surely marvel that when the flowers were blooming in June 2004, we would be observing transits of planets around other stars, with plans afoot to launch spacecraft just for that purpose. What the state of science will be with the next transit pair in 2117 and 2125, we cannot predict, any more than Harkness could have predicted orbiting spacecraft, nanotechnology, or electronic computers.

\section{References}

Clerke, A. 1902 History of Astronomy during the Nineteenth Century, chapter 6, A. and C. Black.

Dick, S.J. 2003 Sky and Ocean Joined: The U. S. Naval Observatory, 1830-2000, 238-273, Cambridge.

Harkness, W. 1883 Address by William Harkness, Proceedings of the AAAS 31st Meeting, August 1882, 77.

Harkness, W. 1891. The Solar Parallax and its Relation Constants in Washington Observations for 1885, Appendix III.

Harkness, W. 1894. On the Magnitude of the Solar System, Astronomy and Astro-Physics, 13, 605-626.

Newcomb, S. 1870 On the mode of Observing the coming transits of Venus, American Journal of Science. 50, 74-83.

Newcomb, S. 1872 On the application of photography to the observation of the transits of Venus In Papers Relating to the Transit of Venus in 1874, Part I, pp. 14-25. U. S. Transit of Venus Commission.

Todd, D. 1881. The Solar Parallax as derived from the American photographs of the transit of Venus, 1874, American Journal of Science, 21, 491-493.

U. S. Naval Observatory 1875 Annual Report, 80-81 


\section{Discussion}

Wayne Orchiston: Would you like to make any comment, Steve, about any surviving relics from the 1874 transit stations, in the light of the paper that's just been published?

STEve Dick: Yes, there happens to be a nice paper in the Journal of Astronomical History and Heritage about Campbell Town. There are relics, but I think probably the best relics that still exist are at the Campbell Town, Tasmania, site. I don't recall what all is still there. There are foundations. Is there a pier there? I don't know any other site from the 19th-century expeditions of any country that still has that number of artefacts unless somebody can correct me on that.

MARY BRÜCK: That wonderful table you showed at the end I think is most interesting. The astronomical one that has the most weight is the heliometer observations of minor planets. Now, the very first one made was done during the Venus transit in Mauritius by Gill, in 1874. When they went on that expedition Lord Lindsay had every possible type of equipment, but Gill knew that this new method was the thing, and he wasn't really worried about the Transit of Venus. He observed Juno, got a result, and published that result, and then, I think, he observed Mars two years later, and then they began wholesale observations of minor planets which turned out to be the better way. So I'm very glad to see that it got weight 20 as against weight 2 for the normal Transit of Venus observations.

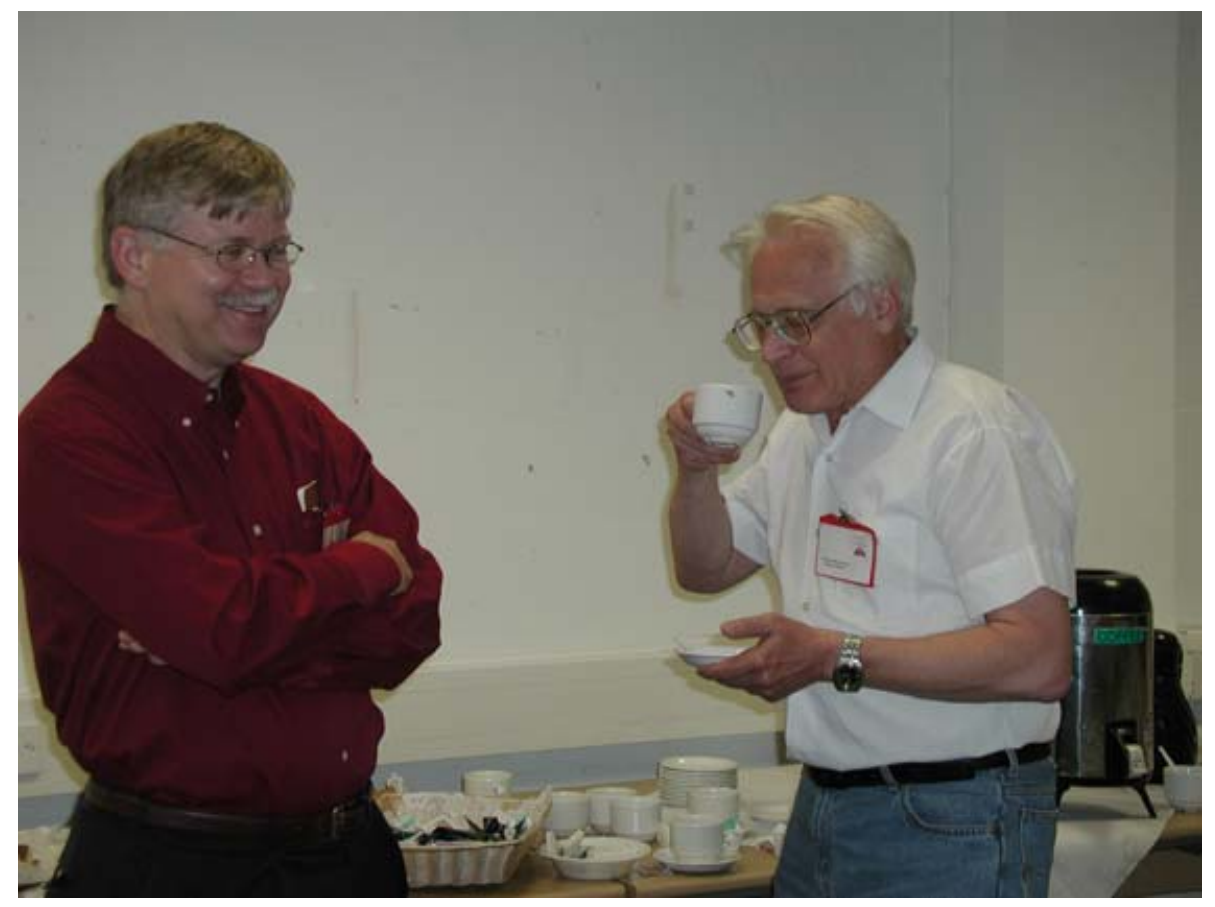

Steve Dick and Mikhail Marov 